\title{
Influence of subject discontinuation on long-term nonvertebral fracture rate in the denosumab FREEDOM Extension study
}

\author{
Jonathan D. Adachi ${ }^{1 *}$, Henry G. Bone ${ }^{2}$, Nadia S. Daizadeh ${ }^{3}$, Paula Dakin ${ }^{3}$, Socrates Papapoulos ${ }^{4}$, Peyman Hadji ${ }^{5}$, \\ Chris Recknor ${ }^{6}$, Michael A. Bolognese ${ }^{7}$, Andrea Wang ${ }^{3}$, Celia J. F. Lin ${ }^{3}$, Rachel B. Wagman ${ }^{3}$ and Serge Ferrari ${ }^{8}$
}

\begin{abstract}
Background: Denosumab treatment for up to 8 years in the FREEDOM study and Extension was associated with low fracture incidence. It was not clear whether subjects who discontinued during the study conduct had a higher risk of fracture than those who remained enrolled, thereby underestimating the true fracture risk for the entire trial cohort. Thus, we explored the influence of early withdrawals on nonvertebral fracture incidence during the Extension study.

Methods: To understand the potential effect of depletion of susceptible subjects on fracture incidence, we first evaluated subject characteristics in patients who were enrolled in the Extension vs those who were not. We subsequently employed a Kaplan-Meier multiple imputation (KMMI) approach to consider subjects who discontinued as if they remained enrolled with a $0 \%, 20 \%, 50 \%$, and 100\% increase in fracture risk compared with participants remaining on study.

Results: Extension enrollees were generally similar to nonparticipants in median age (71.9 and 73.1 years, respectively), mean total hip bone mineral density T-score ( -1.9 and -2.0 , respectively), and probability of fracture risk by Fracture Risk Assessment Tool (FRAX) at FREEDOM baseline (16.9\% and $17.7 \%$ for major osteoporotic fracture and $6.7 \%$ and $7.4 \%$ for hip fracture, respectively). When we assumed a doubled fracture risk (100\% increase) after discontinuation in KMMl analyses, nonvertebral fracture rate estimates were only marginally higher than the observed rates for both the crossover group ( $10.32 \%$ vs $9.16 \%$, respectively) and the long-term group ( $7.63 \%$ vs $6.63 \%$, respectively).
\end{abstract}

Conclusion: The observation of continued denosumab efficacy over 8 years of treatment was robust and does not seem to be explained by depletion of susceptible subjects.

Trial registration: ClincalTrials.gov registration number NCT00523341; registered August 30, 2007

Keywords: Denosumab, Osteoporosis, Selection bias, Extension study, FREEDOM

\section{Background}

Osteoporosis is a chronic disease requiring continuing treatment, and information on the long-term safety and efficacy of treatments is therefore essential. In the 3-year FREEDOM study, treatment with the receptor activator of nuclear factor kappa-B ligand inhibitor denosumab significantly reduced the incidence of vertebral, nonvertebral, and hip fractures compared with placebo [1]. To assess the safety and efficacy of denosumab for up to

\footnotetext{
* Correspondence: jd.adachi@sympatico.ca

'McMaster University, 501-25 Charlton Ave E., Hamilton, ON L8N 1Y2, Canada Full list of author information is available at the end of the article
}

10 years, the FREEDOM study was extended. FREEDOM subjects who were eligible and desired to participate in the Extension were transitioned to denosumab if they had formerly received placebo (crossover group) or continued denosumab treatment (long-term group). Denosumab treatment for up to 8 years was associated with low fracture incidence, continued bone mineral density (BMD) increases, and an adverse event profile similar to what was previously reported [2-6].

The interpretation of the continued low incidence of fractures in the Extension study is limited by the lack of a placebo control group as a reference for the incidence 
of fracture in untreated subjects. Therefore, it is conceivable that changes in study population characteristics might affect interpretation of efficacy and safety outcomes. Subjects may discontinue participation in an osteoporosis clinical trial for a variety of reasons. The nature of long-term follow-up with prescribed visits may prove to be a hindrance in an aging population. In addition, the occurrence of fracture or adverse events may discourage participation. As in all long-term studies, subject discontinuation has the potential to bias results through the depletion of available susceptible subjects.

The primary aim of the present analyses [7, 8] was to evaluate the possible influence of early withdrawals on nonvertebral fracture incidence during the Extension study. For this evaluation, we used a Kaplan-Meier multiple imputation (KMMI) approach [9]. We created four scenarios, where we assumed different increases in fracture risk for the subjects who discontinued the Extension study early compared to the participants who remained on study. We then compared results from the KMMI scenarios to those obtained from the Extension primary analyses.

\section{Methods}

\section{Study design}

As described previously, FREEDOM was a phase 3, multicenter, randomized, double-blind, placebo-controlled study with a duration of 3 years [1]. Subjects were randomized to receive either denosumab $60 \mathrm{mg}$ or placebo by subcutaneous (SC) injection every 6 months. In the Extension, all subjects were to receive denosumab $60 \mathrm{mg} \mathrm{SC}$ every 6 months for a total of 7 years (Additional file 1). Description of the Extension study has been published elsewhere [2,3] and is summarized briefly. This manuscript includes data from the first 5 years of the Extension, representing up to 8 years of denosumab treatment for the long-term group and up to 5 years of denosumab treatment for the crossover group.

Key eligibility criteria to participate in the Extension required that the patients:

- did not discontinue investigational medicine and completed the 36-month visit in the FREEDOM study,

- did not miss more than one dose of investigational medicine during the FREEDOM study, and

- provided consent to participate in the Extension.

A full list of criteria is shown in Additional file 2. We note that T-score thresholds, part of the eligibility criteria in the FREEDOM study to identify postmenopausal women with osteoporosis, were not required for subjects to be eligible for enrollment in the Extension.

\section{Statistical analysis}

Subject characteristics were assessed descriptively over time in subjects who enrolled in the FREEDOM study, those who enrolled in the Extension, and those who remained in the Extension study at the end of year 8 . Characteristics of subjects at the FREEDOM study baseline were also assessed descriptively in subjects who enrolled in the Extension and in subjects who did not participate in the Extension. In addition, the most frequent reasons for study discontinuation were compared descriptively between the FREEDOM study and its Extension.

The effect of denosumab on long-term nonvertebral fracture risk was assessed by Kaplan-Meier estimate of time to first nonvertebral fracture over the first 5 years of the Extension (up to 8 years of denosumab treatment). Cumulative estimates and 95\% confidence intervals are reported at the yearly time points. Vertebral fractures are not included in these analyses, as they were ascertained by radiography at specified intervals and were not amenable to time-to-event analysis.

Sensitivity analyses were undertaken to assess the robustness of the observed Kaplan-Meier estimates of nonvertebral fracture incidence over time. The goal of these sensitivity analyses was to evaluate the possible impact of unknown fracture status (outcome) for subjects who withdrew from the study before experiencing an incident nonvertebral fracture. These analyses employed a KMMI approach for sensitivity analyses of time-to-event data with possibly informative censoring [9]. Informative censoring occurs when subjects who discontinued are either more or less likely to experience the specific event than the remaining individuals in the future. In the current analysis, the specific event of interest is nonvertebral fracture. The KMMI approach imputes fracture status for the discontinued subjects during their unobserved remaining time as if they continued to be followed until the end of the study. A unique feature of this KMMI approach is allowance for the incorporation of various assumed increases in nonvertebral fracture risk for discontinued subjects after study discontinuation relative to the fracture risk of subjects remaining on study when imputing fracture status. Multiple imputation data sets were analyzed individually with the conventional KaplanMeier method, and the results from these separate analyses were then combined using the method of Rubin [10].

We chose four different scenarios of fracture risk-increases of $0 \%, 20 \%, 50 \%$, and $100 \%$ in fracture risk after discontinuation for the subjects who withdrew before experiencing a nonvertebral fracture compared with the subjects who remained in the trial, with the highest assumption (ie, 100\%) representing a doubled fracture risk after withdrawal. As judged by baseline characteristics and Fracture Risk Assessment Tool (FRAX), a 100\% increase in fracture risk (doubling of the risk) was 
determined to be a reasonable "worst-case" scenario for these participants, because subjects who enrolled in the FREEDOM trial were not a particularly high-risk population $[1,11]$, and the subjects had few comorbid conditions. For each scenario, 50 imputations were performed.

\section{Results}

\section{Subject disposition through extension year 5}

The numbers of subjects participating in the FREEDOM study and its Extension are shown in Fig. 1. Eighty-three percent of subjects completed the FREEDOM study (6478/7808), of whom 8\% (550) were ineligible to participate in the Extension; the most common reason was missing more than one dose of investigational medicine during the FREEDOM study, $n=421$. Of those who were eligible ( $n=5928), 1378(23 \%)$ chose not to participate in the Extension. Thus, $77 \%$ of eligible subjects $(n=4550)$ enrolled in the Extension study. Hence, of the original 7808 subjects who participated in FREEDOM, 3258 (42\%) subjects did not participate in the Extension (Extension nonparticipants). At the end of Extension year 5, 3004 subjects (66\% of the Extension baseline population or 38\% of the original FREEDOM population) remained enrolled in the study.

\section{Extension enrollees vs nonparticipants}

FREEDOM baseline characteristics for Extension enrollees and nonparticipants are shown in Table 1. The mean age was slightly higher for Extension nonparticipants (73.1 years) compared with Extension enrollees (71.9 years). The proportion of subjects $\geq 70$ years of age was slightly higher in Extension nonparticipants (77\%) compared with Extension enrollees (71\%).

Figure 2a compares the observed age distribution of the Extension enrollees at Extension baseline with the projected age distribution of the entire FREEDOM population if all subjects enrolled into the Extension, and shows a considerable overlap between the age distributions of these two populations. The observed age distribution for Extension enrollees and the projected age distribution for Extension nonparticipants at Extension baseline also overlapped, although the Extension nonparticipant population included older subjects (Fig. 2b).

No substantial differences were observed for other key risk factors for fracture between the enrollees and nonparticipants. Prior nonvertebral fracture incidence was the same (30\%) between the Extension enrollees and nonparticipants, while BMD at the hip was similar, albeit slightly higher, in Extension enrollees compared with nonparticipants (Table 1). The age of subjects increased in a manner generally consistent with the study length, whereby at the start of the FREEDOM study, the median age was 72.0 years; at the end of 3 years, median age was 75.0 years; and after 8 years, median age was 79.0 years (Table 2). Figure 2c compares the projected age of all Extension enrollees at the end of year 8 to the observed age of the subset of subjects who reached the end of year 8 . The difference between the two age distributions reflects a small percentage loss of some of the oldest subjects from the Extension study population. Figure 2d compares the age of the population remaining at the end of year 8 with the projected age of the FREEDOM population at the end of year 8 , showing that the proportion of older subjects who were lost from the study over 8 years remained relatively small. Among the 3004 subjects who remained in the study at the end of year $8,47 \%$ were $\geq 80$ years old, compared with a projected 53\% of Extension enrollees or $56 \%$ of the FREEDOM subjects. When we examined the mean 10-year FRAX probability of fracture at FREEDOM baseline, the fracture probability was similar for Extension enrollees compared with Extension nonparticipants (6.7\% vs $7.4 \%$ for a hip fracture and $16.9 \%$ vs $17.7 \%$ for a major osteoporotic fracture, with femoral neck BMD included in the calculations). Similarly, the baseline FRAX scores for subjects who completed year 8 of the Extension study were somewhat lower than those who discontinued during

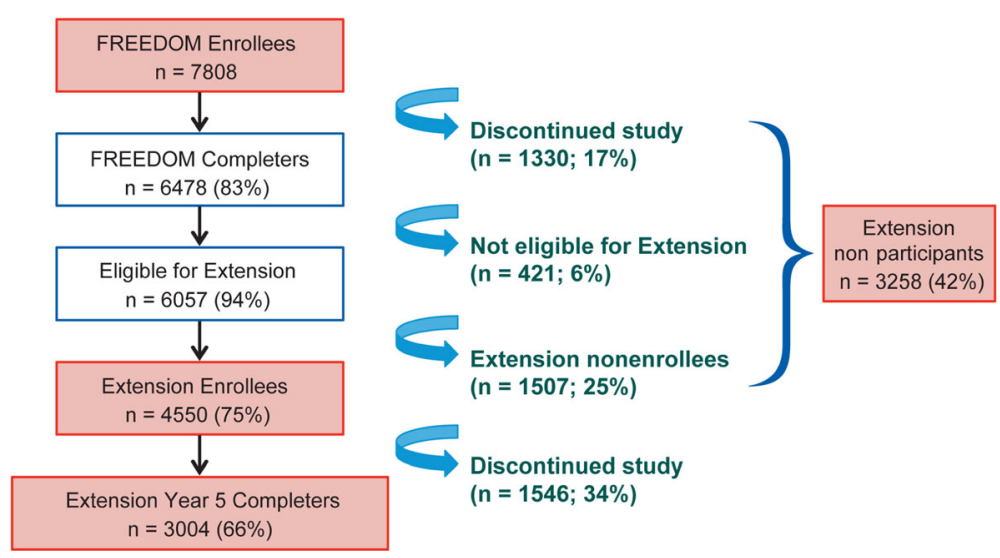

Fig. 1 Evolution of subject sample size over time 
Table 1 Characteristics of Extension enrollees and nonparticipants at FREEDOM baseline

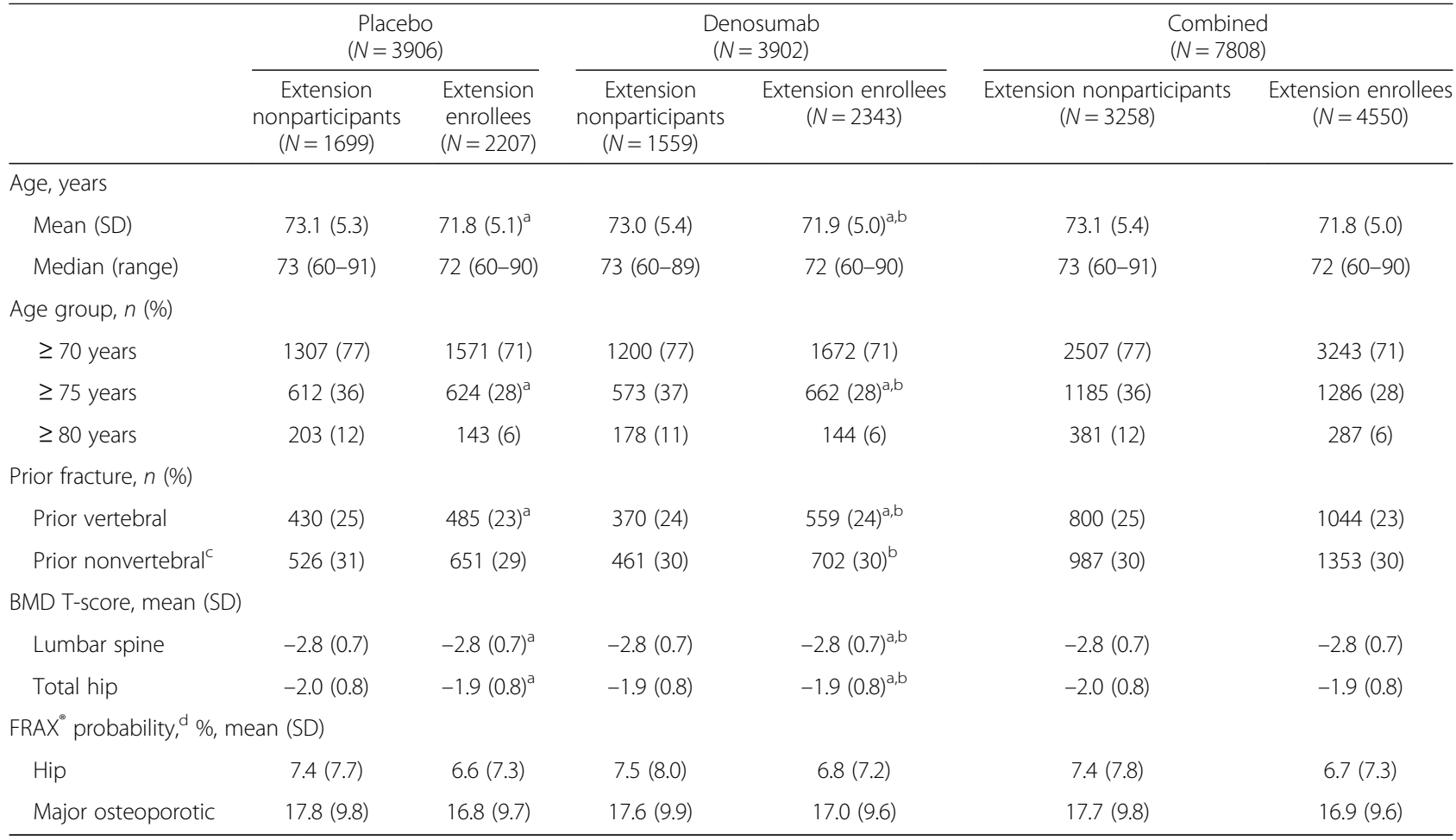

$B M D$ bone mineral density, $F R A X^{\circ}$ Fracture Risk Assessment Tool, $S D$ standard deviation

a Published in Papapoulos et al, 2012 [2]

${ }^{\mathrm{b}}$ Published in Ferrari et al, 2015 [5]

${ }^{\mathrm{c} A t}$ age $\geq 55$ years

${ }^{d} 10$-year probability of fracture calculated with femoral neck BMD

the FREEDOM or Extension studies. The subjects who discontinued had a relative increase in fracture risk of $7 \%$ to $26 \%$ (absolute increase between $1.1 \%$ and 1.8\%; Additional file 3).

\section{Reasons for early withdrawal}

The most frequent reasons for study discontinuation were similar between the FREEDOM study and the Extension (Table 3). Less than 15\% patients had an adverse event listed as the reason for discontinuation, and no more than $1 \%$ in either group had any particular adverse event listed as the reason for discontinuation. Subjects who experienced a fracture during the study were more likely to remain on study compared with those who did not: during the FREEDOM study, discontinuation rates in the placebo group were $12 \%$ in patients with an incident fracture and 19\% in those without an incident fracture and $17 \%$ vs $16 \%$, respectively, in the denosumab group. During the Extension, 28\% of patients with an incident fracture withdrew compared with $35 \%$ of those without an incident fracture.

\section{Kaplan-Meier estimates of nonvertebral fractures}

The cumulative Kaplan-Meier estimates of incidence of nonvertebral fractures during the Extension were
$2.55 \%, 4.45 \%, 6.77 \%, 7.84 \%$, and $9.16 \%$ for the crossover group and $1.49 \%, 2.72 \%, 4.48 \%, 5.92 \%$, and $6.63 \%$ for the long-term group at Extension years 1, 2, 3, 4, and 5, respectively (Fig. 3 and Table 4). The results based on the KMMI approach assuming a range of increases in fracture risk after study withdrawal $(0 \%, 20 \%, 50 \%$, and $100 \%)$ for subjects who withdrew prematurely relative to the subjects with continued follow-up are presented in Table 4 . When the assumed increase in fracture risk was $0 \%$, subjects who prematurely withdrew and those who continued follow-up had the same tendency to experience a nonvertebral fracture in the future (corresponding to the observed original data results). Furthermore, the results obtained using this KMMI approach for the $20 \%, 50 \%$, and $100 \%$ (or double) increased risk of fracture remained similar to the observed data for all scenarios assessed (Table 4).

\section{Discussion}

It is of concern that study subjects who choose to withdraw from participation in an osteoporosis clinical trial may have been more likely to experience an incident fracture on study, a situation often described as depletion of susceptible subjects. Preferential drop-out of susceptible study subjects, potentially resulting in retention 

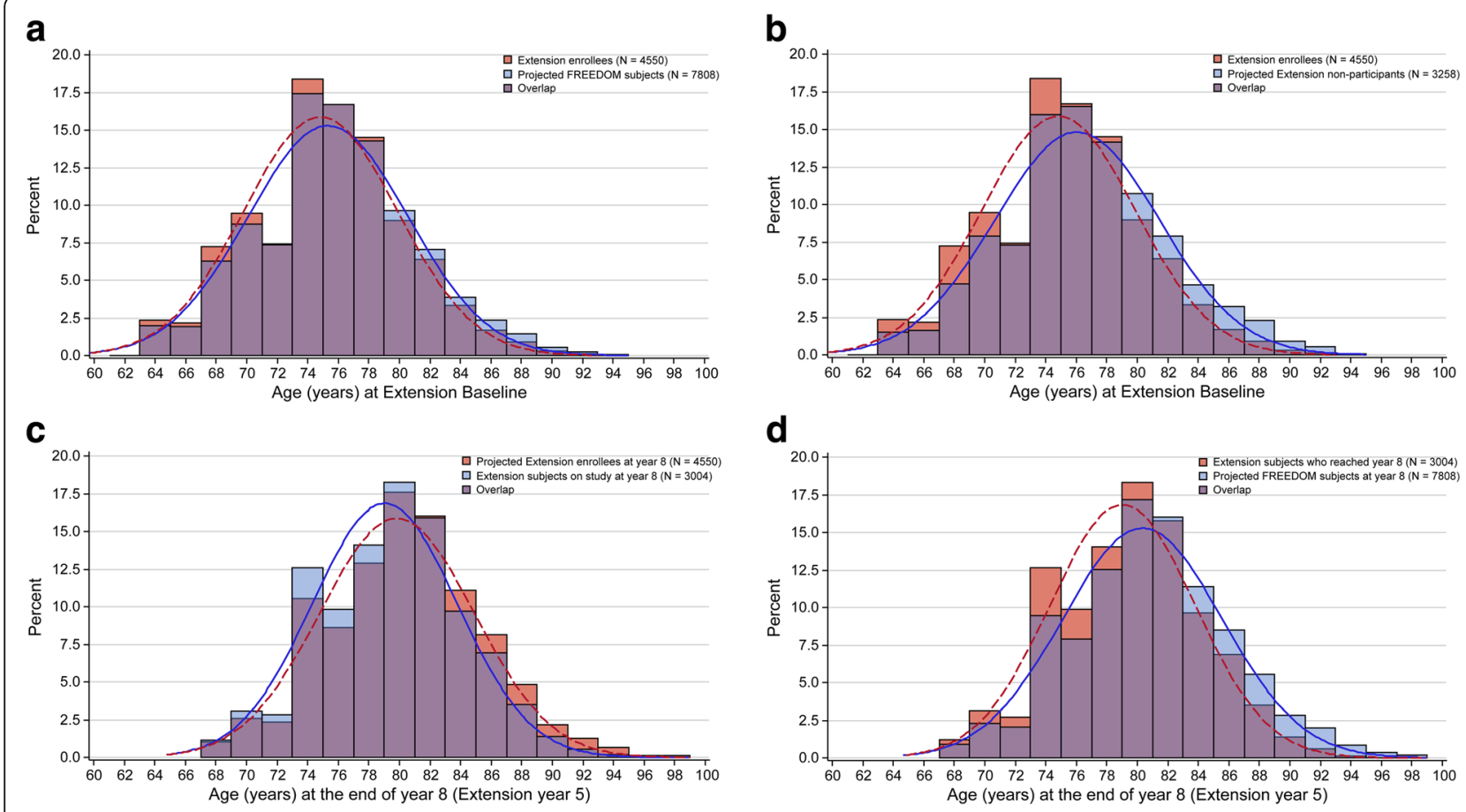

Fig. 2 Age distribution. a Observed age of Extension enrollees vs projected age of FREEDOM population at Extension baseline and overlap between the groups. Lines represent smoothed age distribution. $\mathbf{b}$ Observed age of Extension enrollees vs projected age of Extension nonparticipants at Extension baseline and overlap between the groups. Lines represent smoothed age distribution. $\mathbf{c}$ Projected age of Extension enrollees at year 8 vs observed age of subjects who reached year 8 and overlap between the two groups. Lines represent smoothed age distribution. $\mathbf{d}$ Observed age of subjects who reached the end of year 8 vs projected age of FREEDOM population at the end of year 8; overlap between the groups. Lines represent smoothed age distribution

Table 2 Comparison of subject characteristics over time

\begin{tabular}{|c|c|c|c|c|c|c|}
\hline & \multicolumn{2}{|c|}{ FREEDOM baseline } & \multicolumn{2}{|c|}{ Extension baseline } & \multicolumn{2}{|c|}{ End of year 8} \\
\hline & $\begin{array}{l}\text { Placebo } \\
(N=3906)\end{array}$ & $\begin{array}{l}\text { Denosumab } \\
(N=3902)\end{array}$ & $\begin{array}{l}\text { Crossover denosumab } \\
\qquad(N=2207)\end{array}$ & $\begin{array}{l}\text { Long-term denosumab } \\
\qquad(N=2343)\end{array}$ & $\begin{array}{l}\text { Crossover denosumab } \\
(N=1462)\end{array}$ & $\begin{array}{l}\text { Long-term denosumab } \\
\qquad(N=1542)\end{array}$ \\
\hline \multicolumn{7}{|l|}{ Age, years } \\
\hline Mean (SD) & $72.3(5.2)^{a}$ & $72.3(5.2)^{a}$ & $74.8(5.1)^{\mathrm{b}}$ & $74.9(5.0)^{b}$ & $79.0(4.8)$ & $79.1(4.7)$ \\
\hline Median (range) & $72(60-91)$ & $72(60-90)$ & $75(63-93)$ & $75(63-93)$ & 79 (68-98) & $79(68-94)$ \\
\hline \multicolumn{7}{|l|}{ Age group, $n(\%)$} \\
\hline$\geq 70$ years & $2878(74)$ & $2872(74)$ & $1823(83)$ & $1974(84)$ & $1420(97)$ & $1505(98)$ \\
\hline$\geq 75$ years & $1236(32)^{\mathrm{a}}$ & $1235(32)^{a}$ & $1151(52)^{b}$ & $1258(54)^{b}$ & $1160(79)$ & $1255(81)$ \\
\hline$\geq 80$ years & $346(9)$ & $322(8)$ & $379(17)$ & $407(17)$ & $676(46)$ & $737(48)$ \\
\hline \multicolumn{7}{|l|}{ Prior fracture, $n(\%)$} \\
\hline Prior vertebral & $915(23)^{a}$ & $929(24)^{a}$ & $551(25)^{\mathrm{b}, \mathrm{c}}$ & $573(24)^{b, c}$ & NA & NA \\
\hline Prior nonvertebral ${ }^{d}$ & $1177(30)$ & $1163(30)$ & $754(34)^{c}$ & $780(33)^{c}$ & NA & NA \\
\hline \multicolumn{7}{|l|}{ BMD T-score, mean (SD) } \\
\hline Lumbar spine & $-2.8(0.7)^{\mathrm{a}}$ & $-2.8(0.7)^{\mathrm{a}}$ & $-2.8(0.8)^{b}$ & $-2.1(0.8)^{b}$ & $-1.9(0.9)$ & $-1.6(0.9)$ \\
\hline Total hip & $-1.9(0.8)^{\mathrm{a}}$ & $-1.9(0.8)^{\mathrm{a}}$ & $-1.9(0.8)^{b}$ & $-1.5(0.8)^{b}$ & $-1.5(0.8)$ & $-1.3(0.8)$ \\
\hline
\end{tabular}

$B M D$ bone mineral density, NA not applicable (because the prior fractures cannot be defined at the end of the treatment), $S D$ standard deviation

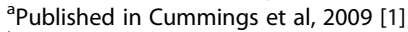

bPublished in Papapoulos et al, 2012 [2]

Includes incident fractures during FREEDOM

${ }^{\mathrm{d}}$ At age $\geq 55$ years 
Table 3 Top reasons for discontinuation during FREEDOM and during the Extension

\begin{tabular}{|c|c|c|c|c|}
\hline & \multicolumn{2}{|c|}{$\begin{array}{l}\text { FREEDOM } \\
\text { (Years 1-3) } \\
\end{array}$} & \multicolumn{2}{|c|}{$\begin{array}{c}\text { Extension year } 5 \\
\quad(\text { Years 1-5) }\end{array}$} \\
\hline & $\begin{array}{l}\text { Placebo } \\
(N=3906)\end{array}$ & $\begin{array}{l}\text { Denosumab } \\
(N=3902)\end{array}$ & $\begin{array}{l}\text { Crossover denosumab } \\
\quad(N=2207)^{\mathrm{a}}\end{array}$ & $\begin{array}{l}\text { Long-term denosumab } \\
\qquad(N=2343)^{\mathrm{a}}\end{array}$ \\
\hline Reasons for discontinuation, $n(\%)$ & $700(18)$ & $630(16)$ & 745 (34) & $801(34)$ \\
\hline Consent withdrawn & $403(10)$ & $344(9)$ & $325(15)$ & $337(14)$ \\
\hline Other & $20(1)$ & $32(1)$ & $170(8)^{b}$ & $184(8)^{b}$ \\
\hline Adverse event & $81(2)$ & $93(2)$ & $93(4)$ & $115(5)$ \\
\hline Death & $78(2)$ & $62(2)$ & $64(3)$ & $80(3)$ \\
\hline Lost to follow-up & $57(1)$ & $57(1)$ & $60(3)$ & $46(2)$ \\
\hline
\end{tabular}

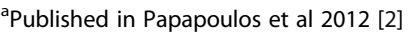

${ }^{b}$ Includes discontinuation after a protocol amendment to extend the Extension for an additional 5 years, which was associated with an increased discontinuation rate at the end of Extension year 2

of a cohort of "healthier" participants (a so-called "healthy cohort effect"), could influence fracture rates observed in any long-term osteoporosis study, including the Extension study. Results of the first 5 years of the Extension (up to 8 years of denosumab for the long-term group and up to 5 years for the crossover group) have shown that longer treatment with denosumab provides continued BMD gains without therapeutic plateau and sustained low fracture incidence $[2,3,6]$. The present analysis attempted to evaluate whether these results reflected continued benefit from denosumab treatment or were the result of a loss of subjects susceptible to fracture over time within the Extension study.

To further understand the implication of early withdrawal of subjects on fracture outcomes during the Extension, we employed a KMMI method for time-to-event data. This analysis was designed to assess the robustness of the nonvertebral fracture results obtained if the subjects who withdrew early before experiencing an incident nonvertebral fracture had remained on study. The KMMI approach used here is an alternative to the traditional clinical trial approach, wherein the status observed upon premature study withdrawal is analyzed (or carried forward) as the final outcome of the study.

The cumulative KMMI estimates of nonvertebral fracture incidence obtained over time remained low and similar to the observed data, even when we assumed that the subjects who withdrew early from the Extension study without an incident fracture had double the fracture risk after study withdrawal compared with the subjects who stayed on study. The baseline mean FRAX probability for subjects who withdrew early was somewhat higher than the baseline mean $\mathrm{FRAX}^{\circ}$ probability of subjects who continued through year 8 , corresponding to a "worst-case" relative increase in fracture risk of $26 \%$. Consequently, a $100 \%$ increase, or doubling, in fracture risk is a reasonable "worst-case" scenario for the subjects enrolled in the FREEDOM trial. Therefore, the observation of continued denosumab efficacy throughout the Extension study cannot be explained by early withdrawal of subjects with increased fracture risk.

The sensitivity analysis presented here is one potential method for estimating the impact of early withdrawals on a study outcome measure. A virtual twin analysis [12],
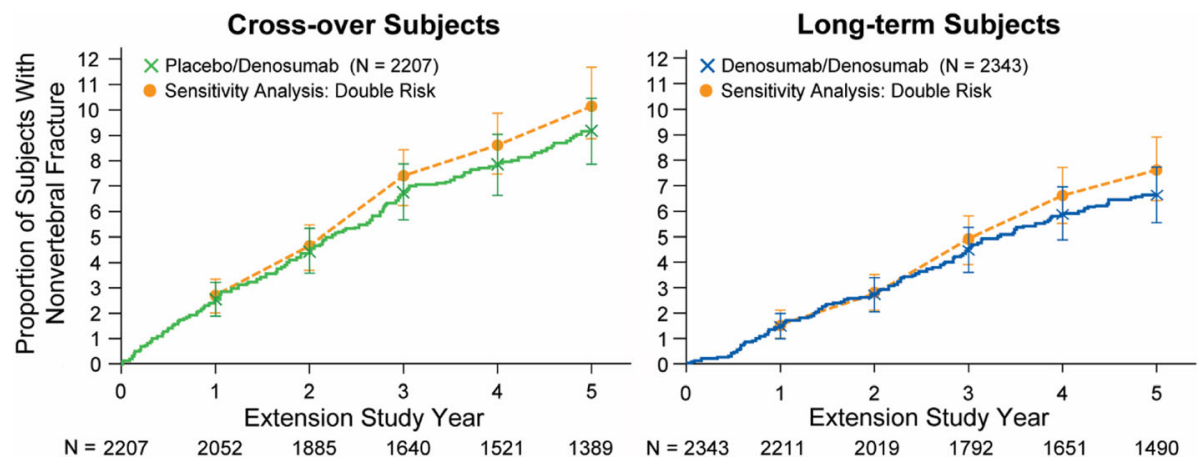

Fig. 3 Observed fracture incidence vs Kaplan-Meier estimated fracture incidence in sensitivity analyses. We compared the observed cumulative fracture incidence in crossover and long-term denosumab-treated subjects up to Extension year 5 (year 8 overall) vs the Kaplan-Meier estimated fracture incidence using a multiple imputation approach with the assumption that subjects who withdrew had double the fracture risk after study discontinuation compared with those who remained on the study. $N$ is the number of subjects who remained at risk at the beginning of each year 
Table 4 Sensitivity analyses for incidence of nonvertebral fractures in crossover (a) and long-term (b) subjects

a Incidence $(95 \% \mathrm{Cl})$ of nonvertebral fractures in crossover subjects

\begin{tabular}{l|c|ccc|c}
\hline Extension & Observed in & \multicolumn{3}{c}{ Sensitivity analyses-estimated with multiple imputation } \\
& enrollees & $0 \%$ & $20 \%$ & $50 \%$ & Double Fx risk, 100\% \\
\cline { 2 - 6 } & $2.55(1.89-3.22)$ & $2.55(1.89-3.22)$ & $2.56(1.90-3.23)$ & $2.58(1.91-3.25)$ & $2.61(1.93-3.29)$ \\
\hline Year 1 & $4.45(3.57-5.33)$ & $4.44(3.57-5.32)$ & $4.47(3.59-5.35)$ & $4.52(3.63-5.41)$ & $4.59(3.69-5.49)$ \\
Year 2 & $6.77(5.67-7.88)$ & $6.74(5.66-7.82)$ & $6.84(5.75-7.93)$ & $7.01(5.90-8.13)$ & $7.31(6.15-8.47)$ \\
Year 3 & $7.84(6.64-9.03)$ & $7.79(6.62-8.95)$ & $7.95(6.76-9.14)$ & $8.20(6.99-9.40)$ & $8.60(7.35-9.84)$ \\
Year 4 & $9.16(7.86-10.47)$ & $9.14(7.87-10.41)$ & $9.38(8.09-10.67)$ & $9.75(8.41-11.09)$ & $10.32(8.93-11.71)$ \\
Year 5 & & & & &
\end{tabular}

$\mathrm{Cl}$ confidence interval, $\mathrm{Fx}$ fracture

b Incidence $(95 \% \mathrm{Cl})$ of nonvertebral fractures in long-term subjects

\begin{tabular}{|c|c|c|c|c|c|}
\hline \multirow[t]{2}{*}{ Extension } & \multirow{2}{*}{$\begin{array}{c}\text { Observed in } \\
\text { enrollees }\end{array}$} & \multicolumn{4}{|c|}{ Sensitivity analyses-estimated with multiple imputation } \\
\hline & & $0 \%$ & $20 \%$ & $50 \%$ & Double Fx risk, $100 \%$ \\
\hline Year 1 & $1.49(0.99-1.98)$ & $1.49(0.99-1.99)$ & $1.50(1.00-2.00)$ & $1.51(1.01-2.02)$ & $1.54(1.02-2.05)$ \\
\hline Year 2 & $2.72(2.05-3.40)$ & $2.73(2.05-3.41)$ & $2.75(2.07-3.43)$ & $2.79(2.10-3.48)$ & $2.84(2.14-3.54)$ \\
\hline Year 3 & $4.48(3.60-5.36)$ & $4.48(3.60-5.37)$ & $4.56(3.66-5.46)$ & $4.67(3.76-5.59)$ & $4.88(3.94-5.82)$ \\
\hline Year 4 & $5.92(4.89-6.95)$ & $5.91(4.88-6.93)$ & $6.04(5.00-7.09)$ & $6.25(5.19-7.32)$ & $6.61(5.49-7.72)$ \\
\hline Year 5 & $6.63(5.54-7.73)$ & $6.66(5.57-7.74)$ & $6.85(5.74-7.95)$ & $7.12(5.98-8.25)$ & $7.63(6.42-8.85)$ \\
\hline
\end{tabular}

$\mathrm{Cl}$ confidence interval, Fx fracture

A multiple imputation approach was used with varying assumptions (0,20,50, and $100 \%$ [ie, double]) of increased fracture risk after study discontinuation for subjects who withdrew early from the Extension relative to subjects who remained in the study. Colored boxes correspond to data plotted in Fig. 3

conducted after subjects competed 2 years of the Extension study [2], employed a completely different analytical method but led to similar conclusions. This provides further confidence that the observed low fracture incidence over time is the result of denosumab treatment.

We found that Extension nonparticipants had some very slight differences from Extension enrollees for some baseline characteristics. As anticipated, there was a loss of some of the oldest subjects (age $\geq 80$ years) during the Extension because of comorbidities and mortality associated with older age. Nevertheless, nearly half of the participants at the end of year 8 were $\geq 80$ years old, similar to the proportion projected if the entire FREEDOM population had remained on study through year 8 without adjustment for expected mortality. Further, we demonstrated that preferential loss of subjects who experienced an incident fracture did not occur as we had hypothesized.

\section{Conclusions}

These results show that the observed fracture incidence in the Extension study cannot be explained by depletion of susceptible subjects or, put another way, retention of a healthy cohort of participants. Rather, the results suggest that the low nonvertebral fracture incidence reflects the effect of long-term denosumab treatment, in the context of an aging population.

\section{Additional files}

Additional file 1: Design of FREEDOM and the Extension study. Q6M once every 6 months, SC subcutaneous. (DOCX $28 \mathrm{~kb}$ )

Additional file 2: Eligibility criteria for the Extension study. (DOC $143 \mathrm{~kb}$ ) Additional file 3: FREEDOM baseline FRAX scores for subjects who continued through year 8 compared with those who did not continue through year 8 . The 10-year probability of fracture calculated with femoral neck BMD. BMD bone mineral density, FRAX Fracture Risk Assessment Tool, SD standard deviation. (DOC 29 kb)

Additional file 4: Institutional review boards and ethics committees for the Extension study. (DOC $120 \mathrm{~kb}$ )

Abbreviations

BMD: Bone mineral density; Cl: Confidence interval; FRAX: Fracture Risk Assessment Tool; Fx: Fracture; KMMl: Kaplan-Meier multiple imputation; NA: Not applicable; Q6M: Once every 6 months; SC: Subcutaneous; SD: Standard deviation 


\section{Acknowledgments}

Wanda J Krall, PhD, funded by Amgen Inc., and Amy Foreman-Wykert, PhD, of Amgen Inc. assisted in the writing of this manuscript. Formatting assistance was provided by Gurpreet Kaur, CACTUS Communications, on behalf of Amgen Inc.

\section{Funding}

This work was supported by Amgen Inc. The sponsor was involved in the study design; in the collection, analysis, and interpretation of data; in the writing of report. All authors were involved in the decision to submit the article for publication.

\section{Availability of data and materials}

The data that support the findings of this study are available from Amgen Inc. but restrictions apply to the availability of these data, which were used under license for the current study, and so are not publicly available. Data are however available from the authors upon reasonable request and with permission of Amgen Inc. Data requests may be made by email to datasharing@amgen.com.

\section{Authors' contributions}

JDA, HGB, SP, PH, MB, and SF enrolled patients in the FREEDOM study and Extension; AW and ND performed the statistical analysis; $P D, C L, R W$ participated in the analysis conceptualization; JDA, HGB, SP, PH, MB, SF, AW, PD, CL, and RW interpreted the results and critically revised the manuscript for important intellectual content. All authors read and approved the final manuscript.

\section{Competing interests}

JDA has received consulting fees, speaker fees, and research grants from Actavis, Amgen Inc., Eli Lilly, Merck, and Novartis, and consulting fees from AgNovos. HGB has received research funding, consulting and/or speaker fees from Amgen Inc., MSD, and Shire. SP has received consulting and/or speaker fees from Amgen Inc., Axsome, Merck, Novartis, and UCB. PH received research grants, consulting fees, and speaker fees from Amgen Inc., Elli Lilly, Novartis, Pfizer, and Roche. CR is a principal investigator of clinical trials for Amgen Inc, Novartis, and Eli Lilly. MB has received research funding from Amgen Inc., Eli Lilly, and Regeneron and speaker fees from Eli Lilly and Amgen Inc. AW and RBW are employees of Amgen Inc. and hold Amgen Inc. stock. ND, PD, and CJFL were employees of Amgen Inc. while the work was conducted. SF has received consulting fees, speaker fees, and research grants from Amgen Inc., Eli Lilly, Merck, GSK, UCB, Bioiberica, and AgNovos.

\section{Consent for publication}

Not applicable.

\section{Ethics approval and consent to participate}

All procedures performed in studies involving human participants were in accordance with the ethical standards of the institutional and/or national research committee and with the 1964 Helsinki declaration and its later amendments or comparable ethical standard. The protocol was approved by the ethics committees or institutional review boards for each site (see Additional file 4 for a list of ethics committees and institutional review boards), and informed consent was obtained from all individual participants included in the study.

\section{Publisher's Note}

Springer Nature remains neutral with regard to jurisdictional claims in published maps and institutional affiliations.

\footnotetext{
Author details

'McMaster University, 501-25 Charlton Ave E., Hamilton, ON L8N 1Y2, Canada. ${ }^{2}$ Michigan Bone and Mineral Clinic, 22201 Moross Rd, Detroit, MI 48236, USA. ${ }^{3}$ Amgen Inc., One Amgen Ctr Dr., Thousand Oaks, CA 91320, USA. ${ }^{4}$ Leiden University Medical Center, Albinusdreef 2, 2333, ZA, Leiden, Netherlands. ${ }^{5}$ Krankenhaus Nordwest, Steinbacher Hohl 2-26, 60488 Frankfurt am Main, Germany. ${ }^{6}$ United Osteoporosis Centers, 2350 Limestone Pkwy, Gainesville, GA 30501, USA. 'Bethesda Health Research Center, 10215 Fernwood Rd Ste 40, Bethesda, MD 20817, USA. ${ }^{8}$ Geneva University Hospital, Rue Gabrielle-Perret-Gentil 4, 1205 Genève, Switzerland.
}

Received: 30 November 2016 Accepted: 6 April 2017

Published online: 27 April 2017

\section{References}

1. Cummings SR, San Martin J, McClung MR, Siris ES, Eastell R, Reid IR, et al. Denosumab for prevention of fractures in postmenopausal women with osteoporosis. N Engl J Med. 2009;361 (8):756-65.

2. Papapoulos S, Chapurlat R, Libanati C, Brandi ML, Brown JP, Czerwinski E, et al. Five years of denosumab exposure in women with postmenopausal osteoporosis: results from the first two years of the FREEDOM extension. J Bone Miner Res. 2012:27(3):694-701.

3. Bone HG, Chapurlat R, Brandi ML, Brown JP, Czerwinski E, Krieg MA, et al. The effect of three or six years of denosumab exposure in women with postmenopausal osteoporosis: results from the FREEDOM extension. J Clin Endocrinol Metab. 2013:98(11):4483-92.

4. Brown JP, Reid IR, Wagman RB, Kendler D, Miller PD, Jensen JE, et al. Effects of up to 5 years of denosumab treatment on bone histology and histomorphometry: the FREEDOM study extension. J Bone Miner Res. 2014;29(9):2051-6.

5. Ferrari S, Adachi JD, Lippuner K, Zapalowski C, Miller PD, Reginster JY, et al. Further reductions in nonvertebral fracture rate with long-term denosumab treatment in the FREEDOM open-label extension and influence of hip bone mineral density after 3 years. Osteoporos Int. 2015;26:2763-71.

6. Papapoulos S, Lippuner K, Roux C, Lin CJ, Kendler DL, Lewiecki EM, et al. The effect of 8 or 5 years of denosumab treatment in postmenopausal women with osteoporosis: results from the FREEDOM Extension study. Osteoporos Int. 2015;26(12):2773-83.

7. Papapoulos S, Lippuner K, Roux C, Lin CJ, Lewiecki EM, Brandi ML, et al. Effects of up to 8 years of denosumab treatment in women with postmenopausal osteoporosis: Results: from the first 5 years of the FREEDOM extension. Aust J Ageing. 2014;33 Suppl 1:[abstract] 14.

8. Adachi JD, Lin C, Ho PR, M.A. B, Bone HG, Hadji P, et al. Changes in Subject Characteristics in the Denosumab Pivotal Fracture Trial and Its Extension for up to 8 Years. http://acrabstracts.org/abstract/changes-in-subject-characteristicsin-the-denosumab-pivotal-fracture-trial-and-its-extension-for-up-to-8-years/. 2014;2014 ACR/ARHP Annual Meeting:Abstract 2254.

9. Zhao Y, Herring AH, Zhou H, Ali MW, Koch GG. A multiple imputation method for sensitivity analyses of time-to-event data with possibly informative censoring. J Biopharm Stat. 2014;24(2):229-53.

10. Rubin DB. Multiple Imputation for Nonresponse in Surveys. New York: Wiley; 1987.

11. Austin M, Yang YC, Vittinghoff E, Adami S, Boonen S, Bauer DC, et al. Relationship between bone mineral density changes with denosumab treatment and risk reduction for vertebral and nonvertebral fractures. J Bone Miner Res. 2012;27(3):687-93.

12. Vittinghoff $E$, McCulloch CE, Woo C, Cummings SR. Estimating long-term effects of treatment from placebo-controlled trials with an extension period, using virtual twins. Stat Med. 2010;29(10):1127-36.

\section{Submit your next manuscript to BioMed Central and we will help you at every step:}

- We accept pre-submission inquiries

- Our selector tool helps you to find the most relevant journal

- We provide round the clock customer support

- Convenient online submission

- Thorough peer review

- Inclusion in PubMed and all major indexing services

- Maximum visibility for your research

Submit your manuscript at www.biomedcentral.com/submit
C Biomed Central 